\title{
Digital Attendance Register using Raspberry-Pi
}

\author{
G. Tharun kumar, R. Puviarasi
}

\begin{abstract}
Nowadays marking the attendance of the students is a very important work for every staff in every class. The staff has to mark the attendance by manually by seeing the student faces. After verifying the student's, they have to cross check and the register will be submitted to the higher officials by manually. It consumes a lot of time for the processing. Currently, the proposed system is useful for colleges to mark the attendance automatically without any manual dependent. Generally, face is the most identified part for every human. Hence, the proposed work is automatic face recognition system by using raspberry pi and Open CV software. This work involves five methods namely, face detection, face preprocessing, face training, face recognition and attendance marking. The attendance will be marked in the IOT page and used an LCD display for the details of that student.
\end{abstract}

Key words: Raspberry Pi, Open CV, IOT

\section{INTRODUCTION}

Most of the schools round the world apply the attending system to capture student's promptness. However, this paper attending system has several challenges. Passing associate degree attending sheet from one student to the opposite to sign takes time yet as causes distraction. Because of such drawback, some lecturers delay the attending until the top of the category, nonetheless some students could be during a hurry to depart the category in real time, thence they may miss linguistic communication the attending sheet. What is more, there are some students who never return to the category however sign attending by proxy. In some cases, lecturer's decision by names one by one to mark the attending however this technique additionally consume many times. One more drawback is a few students return to category late particularly in the morning categories. Moreover, opening, and shutting of the door throughout the lecture can be terribly heavy for each lecturer and students [1]. Hence, the manual attending system, don't seem to be secure and reliable. Attendance of the students and faculties haves a main role in their performance. By the proposed system, the consistency of attendance will increase. By this the student will be known every aspect of subject and interaction will be increased which will makes a better student [2]. Chronic absence will increase the danger of faculty failing and fast dropout. The maintenance of attendance is insufficient because of subsequent reasons which consumes more time in class hours and the risk of proxies or impersonations.

During this planned system we tend to take the attending victimization face recognition that acknowledges the face of every student throughout the category hours. Here planned the sensible attending watching system supported the face recognition. In compare with the non-biometric and biometric the face recognition technology is better with the distinctive benefits. Every student will possess a different facial identity which cannot be faked by proxies. Moreover, the category academics feels a lot of at home with the coed by their count enhance than the name or roll variety. The followed works has more contributions such as: perfect face choice technique victimization, quality face assessment and face capable illustration victimization deeper convolution network technique. A flexible embedded device is used in the class rooms for attendance.

\section{BLOCK DIAGRAM}

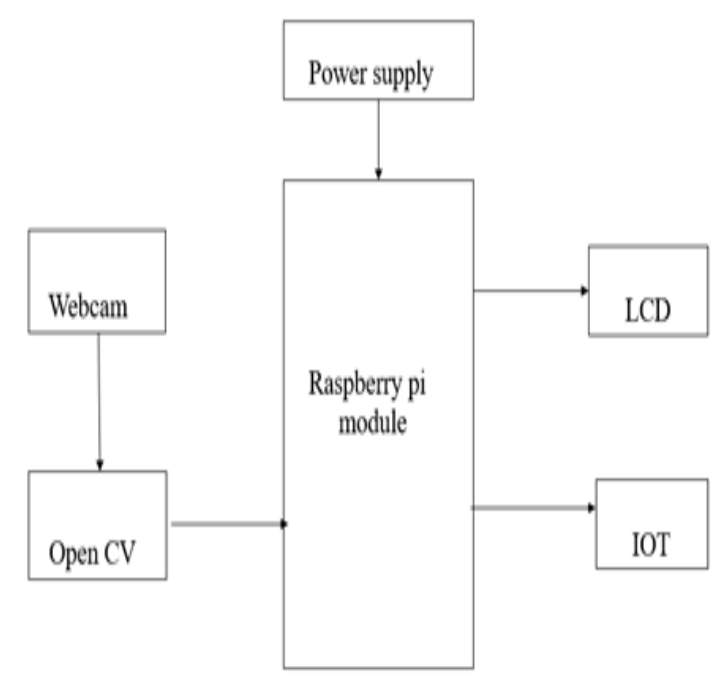

Fig 1: - Block diagram

\section{Raspberry Pi: -}

Generally, Raspberry Pi is in low cost, and it is very small circuit and in a normal visiting card sized computer. It plugs to a normal computer monitor and uses the mouse and keyboard. It is used to learn the programming languages like python, scratch etc. It is equipped with 64-bit processor and ethernet chip for connecting the internet. It consists 4 ports for input and output connection. It is useful for small single board computer.

Revised Manuscript Received on August 14, 2019.

G. Tharun kumar, Department of Electronics and Communication Engineering, Saveetha School of Engineering, Saveetha Institute of Medical and Technical Sciences, Chennai, Tamilnadu, India..

Dr. R. Puviarasi, Department of Electronics and Communication Engineering, Saveetha School of Engineering, Saveetha Institute of Medical and Technical Sciences, Chennai, Tamilnadu, India. 


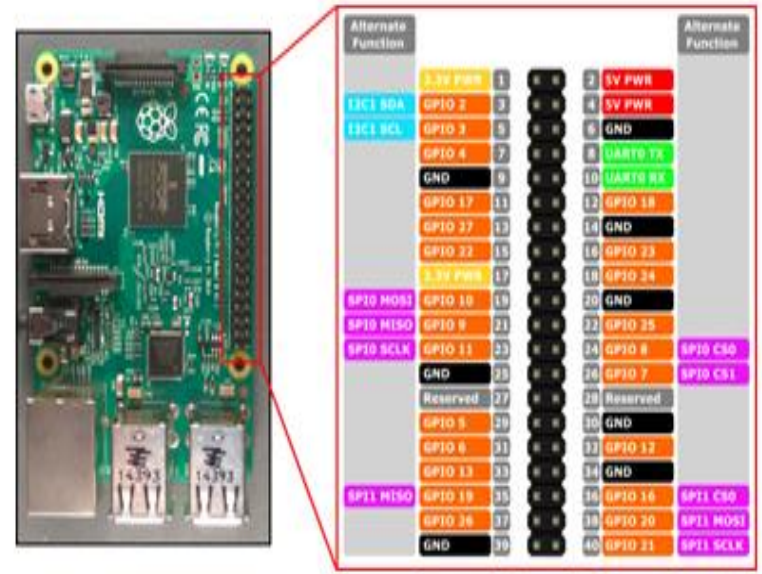

Fig 2: - Raspberry pi pin diagram

\section{Internet of things: -}

Internet of Things (IOT) contains the network of things like vehicles, buildings, physical accessories etc. It uses the embedded hardware components with electronics, software components and sensors etc. for the connectivity of networks and it enables the data exchange. It allows the objects to be sensed and remotely controlled with in the network and creates the direct integration to the physical world of objects and to the computer dependent systems with the larger accuracy and efficiency. The major use of this is for smart technology development in the homes, transportation, cities.

\section{Camera: -}

Elements of a fuzzy set might belong to the set, might not belong to the set, or might belong to a degree. Membership of a crisp set is represented by a bivalent condition. The membership of a fuzzy set is represented by a multivalent condition.

\section{Power Supply: -}

The power provide could be a Primary demand for the project work. The specified DC power provide for the bottom unit further more as for the recharging unit comes from the mains line. For this purposed center tapped secondary of 12 to 12 volts electrical device is employed. From this electrical device we tend to obtaining 5volt power provides.

\section{WORKING PRINCIPLE}

In method is implemented to the Raspberry pi processor. Face recognition is used to open $\mathrm{CV}$ method. In this method the webcam is already taken some images and it store to the database. And it creates the training file. When webcam recognize the face will match the training file if will it match means the details will updated to the IOT webpages. When the staff will give one user name and password that time the camera will on and it recognize the faces.

\section{RESULTS}

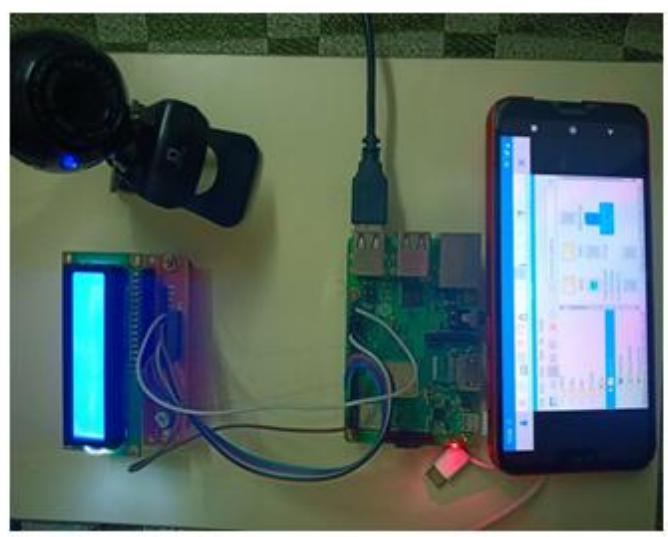

Fig 3: -Output

The fig 3 contains the raspberry pi module, LCD display and a webcam along with the mobile which is acts as a operating system for the module. By using the VNC viewer the raspberry pi operations are controlled and it should be in same network. In the raspberry pi module, the memory card is used to store the data. To run the project three files are to be programmed.

\section{CONCLUSION}

This paper associative attendance system haves a drawback which is caused by the manual strategies. To overcome this draw back we have used the face recognition system that marks the attendance of a specific person by detecting the face. Since the systems are generally failed to acknowledge each face of the scholar in room. We've created the device transportable for straightforward use in school. The attendance is marked within the IOT web content directly with the name. Thus, it should scale back the time for employees for attending. By the present technical developments, the efficiency rate for the system will hyperbolic. This system will be tested by using the alternative techniques of face detection techniques.

\section{REFERENCES}

1. Sajid, Mashhood, Rubab Hussain, and Muhammad Usman. "A conceptual model for automated attendance marking system using facial recognition", Ninth International Conference on Digital Information Management (ICDIM 2014), 2014.

2. Rohit, C., Baburao, P., Vinayak, F., \&Sankalp, S. (2015). Attendance management system using face recognition. International Journal for Innovative Research in Science and Technology, 1(11), 55-58. 